\title{
What lies beneath (the mitral annulus): The geometric implications of restrictive annuloplasty
}

\author{
David D. Yuh, MD, FACS, FACC
}

\author{
From the Department of Surgery, Stamford Hospital, Stamford, Conn. \\ Disclosures: Author has nothing to disclose with regard to commercial support. \\ Received for publication March 1, 2018; accepted for publication March 6, 2018; available ahead of print April 3, \\ 2018. \\ Address for reprints: David D. Yuh, MD, FACS, FACC, Department of Surgery, Stamford Hospital, One Hospital \\ Plaza, PO Box 9317, Stamford, CT 06902 (E-mail: DYuh@stamhealth.org) \\ J Thorac Cardiovasc Surg 2018;156:639-40 \\ $0022-5223 / \$ 36.00$ \\ Copyright (C) 2018 by The American Association for Thoracic Surgery \\ https://doi.org/10.1016/j.jtcvs.2018.03.042
}

Kainuma and colleagues ${ }^{1}$ provide useful clinical insight into the effect of restrictive mitral annuloplasty (RMA) on the subvalvular apparatus in the surgical treatment of functional mitral regurgitation (FMR). Because the impact of RMA on the geometry of the subvalvular apparatus is largely indirect, understanding its true impact on the natural history of FMR and its association with high rates of recurrent FMR has been elusive. Although the authors' finding that changes in interpapillary muscle distance were independently associated with changes in FMR severity has been described, ${ }^{2,3}$ this study provides further granularity in longitudinally examining other geometric parameters of the subvalvular apparatus between patients with and without recurrent FMR. For example, although the anterior and posterior papillary muscle tethering distances similarly decreased among all patients within 1 month after undergoing RMA, recurrent FMR 1 year later was associated with progressive increases in posterior papillary muscle tethering distances, supporting a mechanism of asymmetrical tethering and posteromedial papillary muscle displacement.

One should be cautious in attributing the lower FMR recurrence rate of $25 \%$ observed in this study, compared with rates observed in other larger series, to more aggressive reduction of the annular anteroposterior diameter through annuloplasty ring downsizing. Besides the relatively small patient cohort and retrospective nature of this study, this analysis included patients with mixed FMR causes (ie, nonischemic and ischemic) with correspondingly different preoperative subvalvular apparatus geometries (ie, symmetric vs asymmetric anterior and posterior tethering) and different degrees of coronary revascularization. Moreover, the authors incorporated body surface area in their ringsizing determinations, which was likely not uniformly used in comparative studies. The authors rightly speculate on other potential explanations for the lower observed FMR recurrence rates.

Finally, Kainuma and colleagues ${ }^{1}$ confirmed that the durability of RMA (ie, absence of FMR recurrence) was

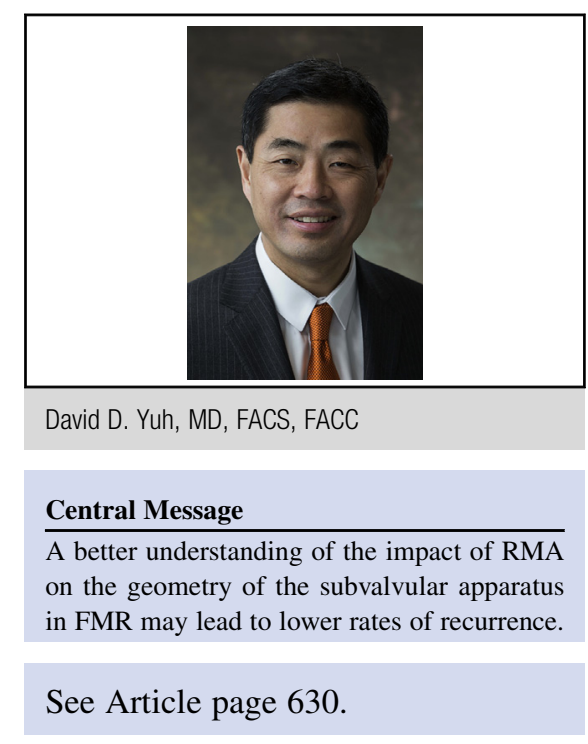

associated with significant reverse left ventricular remodeling and at least partial restoration of subvalvular geometry. The million-dollar question, of course, is why some patients exhibited reverse ventricular remodeling while others did not. It should also be noted that patients developing recurrent FMR after RMA appeared to start with slightly larger left ventricles with lower ejection fractions. It is plausible that these "sicker" ventricles possessed lower potential for reverse remodeling with RMA alone.

It is interesting to speculate whether reverse ventricular remodeling after RMA primarily results from the reduction of chronic volume overload stemming from FMR, from early geometric changes of the subvalvular apparatus imparted by mechanically altering annular conformation, or both to varying degrees. If altering subvalvular geometry in specific ways affects ventricular remodeling to any degree, this study establishes a precedent for potentially identifying specific changes in geometric parameters of the subvalvular apparatus predictive of reverse ventricular remodeling, relief of subvalvular tethering, and reduction of FMR recurrence. Regardless, with recent investigation of several different subvalvular interventional techniques used in combination with RMA for FMR (eg, papillary muscle approximation, papillary muscle relocation, secondary chordal cutting), additional analyses like this, particularly well-controlled prospective studies with larger cohorts, may help rationalize such adjunctive strategies. 


\section{References}

1. Kainuma S, Funatsu T, Kondoh H, Yokota T, Maeda S, Shudo Y, et al. Beneficial effects of restrictive annuloplasty on subvalvular geometry in patients with functional mitral regurgitation and advanced cardiomyopathy. J Thorac Cardiovasc Surg. 2018;156:630-8.e1.

2. Kim K, Kaji S, An Y, Nishino T, Tani T, Kitai T, et al. Interpapillary muscle distance independent affects severity of functional mitral regurgitation in patients with systolic left ventricular dysfunction. J Thorac Cardiovasc Surg. 2014;148:434-40.
3. Roshanali F, Mandegar MH, Yousefinia MA, Rayatzadeh H, Alaeddini F. A prospective study of predicting factors in ischemic mitral regurgitation recurrence after ring annuloplasty. Ann Thorac Surg. 2007;84:745-9.

4. Mihos CG, Xydas S, Yucel E, Capoulade R, Williams RF, Mawad M, et al. Mitral valve repair and subvalvular intervention for secondary mitral regurgitation: a systematic review and meta-analysis of randomized controlled and propensity matched studies. J Thorac Dis. 2017;9(Suppl 7):S582-94. 